\title{
(C) \\ OPEN ACCESS \\ An observational study of nurse staffing ratios and hospital readmission among children admitted for common conditions
}

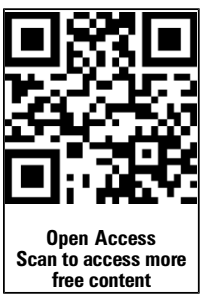

- Additional material is published online only. To view please visit the journal online (http://dx.doi.org/10.1136/bmjqs2012-001610)

${ }^{1}$ Cincinnati Children's Hospital Medical Center, Cincinnati, Ohio, USA

${ }^{2}$ University of Cincinnati College of Nursing, Cincinnati, Ohio, USA

${ }^{3}$ New Jersey Collaborating Center for Nursing, Rutgers University,

Newark, New Jersey, USA

${ }^{4}$ Center for Outcomes Research,

The Children's Hospital of Philadelphia and the University of Pennsylvania Perelman School of Medicine, Philadelphia, Pennsylvania, USA

${ }^{5}$ Center for Health Outcomes and Policy Research, University of Pennsylvania School of Nursing, Philadelphia,

Pennsylvania, USA

\section{Correspondence to} Dr Heather L Tubbs-Cooley, Department of Patient Services, James M. Anderson Center for Health Systems Excellence, Cincinnati Children's Hospita Medical Center, University of Cincinnati College of Nursing 3333 Burnet Ave, MLC 11016, Cincinnati, OH 45229-3039, USA Heather.Tubbs_Cooley@cchmc.org

Received 19 October 2012 Revised 6 February 2013 Accepted 4 April 2013 Published Online First 8 May 2013

To cite: Tubbs-Cooley HL, Cimiotti JP, Silber JH, et al. BMJ Qual Saf 2013;22: 735-742.

\author{
Heather L Tubbs-Cooley, ${ }^{1,2}$ Jeannie P Cimiotti, ${ }^{3}$ Jeffrey H Silber, ${ }^{4}$ \\ Douglas M Sloane, ${ }^{5}$ Linda $\mathrm{H} \mathrm{Aiken}^{5}$
}

\begin{abstract}
Background Hospital patient-to-nurse staffing ratios are associated with quality outcomes in adult patient populations but little is known about how these factors affect paediatric care. We examined the relationship between staffing ratios and all-cause readmission (within 14 days, 15-30 days) among children admitted for common medical and surgical conditions.

Methods We conducted an observational cross-sectional study of readmissions of children in 225 hospitals by linking nurse surveys, inpatient discharge data and information from the American Hospital Association Annual Survey. Registered Nurses ( $N=14$ 194) providing direct patient care in study hospitals $(\mathrm{N}=225)$ and children hospitalised for common conditions ( $N=90$ 459) were included.
\end{abstract}

Results Each one patient increase in a hospital's average paediatric staffing ratio increased a medical child's odds of readmission within $15-30$ days by a factor of 1.11 , or by $11 \%$ (95\% Cl 1.02 to 1.20 ) and a surgical child's likelihood of readmission within 15-30 days by a factor of 1.48 , or by $48 \%(95 \% \mathrm{Cl} 1.27$ to 1.73$)$. Children treated in hospitals with paediatric staffing ratios of $1: 4$ or less were significantly less likely to be readmitted within 15-30 days. There were no significant effects of nurse staffing ratios on readmissions within 14 days.

Discussion Children with common conditions treated in hospitals in which nurses care for fewer patients each are significantly less likely to experience readmission between 15 and 30 days after discharge. Lower patient-to-nurse ratios hold promise for preventing unnecessary hospital readmissions for children through more effective predischarge monitoring of patient conditions, improved discharge preparation and enhanced quality improvement success.

\section{INTRODUCTION}

Preventing unnecessary hospital readmission is increasingly important to hospitals as they face the prospect of nonpayment, ${ }^{12}$ and readmission as a measure of hospital quality is a central focus of large-scale quality improvement initiatives such as the Centres for Medicare and Medicaid Services' Community-based Care Transitions programme. ${ }^{3}$ In paediatrics, current evidence on hospital readmission is generally descriptive with an emphasis on patient-specific factors, including medical complexity and demographics. ${ }^{4-11}$ Few studies have examined relationships between hospital systems factors and readmission among children, and those that have are focused on standardised clinical pathways for disease-specific conditions, ${ }^{12}$ fixed characteristics of hospitals such as location and children's hospital designation ${ }^{13-15}$ and the performance of state-level paediatric healthcare systems. ${ }^{16}$ A 2010 study by Lorch and colleagues highlights the challenge of attributing readmission to hospital quality; variation in readmission among preterm infants was explained by factors related to both inpatient and outpatient care, including the quality of the outpatient practice that the infant was discharged to. ${ }^{17}$ Additionally, the preventability of paediatric hospitalisations may be much lower than in adult patients. ${ }^{18}$ However, to the extent that the quality of inpatient care has potential to influence hospital readmission among children, we focused our attention on a modifiable characteristic of hospitals that has been linked to quality outcomes in adult patients but is relatively unstudied in paediatrics: patient-to-nurse staffing ratios. 
The potential for nurse staffing to influence hospital readmissions may be explained by the role of bedside nurses in supporting appropriate discharge. During the inpatient stay, nurses identify and respond to changes in a patient's condition; educate patients and families on home management of diseases, devices, wounds and medications; and act as a final buffer during the transition from inpatient to outpatient care. A 2008 study by Weiss and colleagues found that better quality of discharge teaching by nurses was predictive of increased readiness for discharge among parents of hospitalised children, decreased coping difficulty in the weeks following discharge, and ultimately, fewer postdischarge readmissions and emergency department visits. ${ }^{19}$ Staffing levels likely impact the amount of time nurses are available to engage in these core processes as well as their effectiveness in doing so. There is a robust research literature documenting an association between more favourable nurse staffing and a range of patient outcomes including mortality, adverse events and satisfaction with care. ${ }^{20-25}$ Additionally, registered nurse (RN) staffing levels have been shown to directly be associated with hospital readmissions in adult patients cared for on medicalsurgical units. ${ }^{26} 27$ However, the extent to which nurse staffing levels relate to paediatric readmission was previously unstudied.

The purpose of this study was to examine associations between hospital nurse staffing ratios and readmission among children admitted for common medical and surgical conditions. We studied common conditions for the purposes of focusing on diagnoses and procedures where a readmission is generally considered undesirable and possibly preventable. We departed from traditional studies of 30-day readmission to analyse readmission in discrete time intervals within the first 30 days after discharge: within 14 days and 15-30 days. This decision was prompted by clinical observations that rehospitalisation in the immediate postdischarge period may be more related to the quality of hospital care than rehospitalisations beyond the first 2 weeks, which may be more influenced by non-hospital characteristics. We hypothesised that better staffing ratios within hospitals (eg, fewer patients per nurse on average) would be associated with reduced odds of readmission during both time intervals, with the strongest and most significant effects evident within the first 14 days after hospital discharge.

\section{METHODS}

\section{Design}

We conducted an observational, cross-sectional study using 2006 data from three sources: RN survey data from California, Florida, New Jersey and Pennsylvania; state-based inpatient discharge data for hospitals in the corresponding states; and the American Hospital Association Annual Survey.

\section{Sample and setting}

Nurses

Using licensure lists provided by state boards of nursing, we mailed surveys to a $40 \%$ random sample of RNs in CA and PA, a 50\% random sample of RNs in NJ and a 25\% random sample of RNs in FL. Details of the nurse survey design and implementation are published elsewhere. ${ }^{20}$ The initial survey response rate was 39\%. A subsequent survey of randomly selected non-responders $(n=650$ in California, $n=650$ in Pennsylvania) achieved a 91\% response rate and revealed no differences on measures of workload between the groups. ${ }^{28}$ Respondents reported a variety of employment statuses and settings, though in this study, we report on nurses providing direct patient care within hospitals. We asked nurses to provide the name of their employing hospital, to identify the type of unit they worked within (medical, surgical, intensive care unit, paediatric), and to report the number of patients they cared for on their last shift worked. Identification of hospitals enabled aggregation of nurses' responses within institutions, which allowed us to create hospital-level measures of nurse-to-patient staffing ratios. Identification of units enabled us to create a paediatric-specific measure of nurse staffing, described in more detail below.

Patients

Discharge data from state agencies for children ages 1-17 were used in the calculation of readmission if the primary diagnosis or procedure code represented a common condition and children were treated in hospitals meeting inclusion criteria. Medical conditions, surgical procedures and comorbidities (see online appendix) were identified based on diagnosis-related group (DRG) and International Classification of Diseases and Related Health Problems, Ninth Revision (ICD-9) codes as defined in previous publications. ${ }^{15}{ }^{29}$ Children hospitalised during the fourth quarter of 2006 in the state of Florida were excluded due to the lack of explicit admission and discharge dates in the patient record $(n=5181)$. Children missing a key socioeconomic index risk adjustment variable were also excluded from the analysis $(n=2123)$. Lastly, we excluded children who experienced a readmission beyond 30 days postdischarge $(n=4389)$ in order to focus our analyses on readmission within the first 30 days.

Hospitals

Included hospitals were all non-federal acute-care facilities (excluding psychiatric hospitals) in the four states with at least 50 paediatric discharges per year for any of the conditions of interest and with at least 10 staff nurse respondents. Previous research showed that a minimum of 10 nurse respondents per hospital produced reliable aggregate nursing self-report measures. ${ }^{30}$ Most hospitals in the analysis had significantly more than 10 nurses, with the average number of nurses per hospital being 63 . 


\section{Measures}

Patient-to-nurse staffing ratios were calculated based upon nurse reports of the number of patients cared for on their last shift worked. Prior research shows that nurses' self-reports of the number of patients assigned to their care are reliable and have better predictive validity than other commonly used sources to derive staffing measures such as administrative data. ${ }^{31}$ Hospital-level averages of nurses' reports of the total number of patients cared for were calculated (1) for all direct patient care nurses on all units and (2) for direct patient care nurses who reported working on a paediatric unit. Thus, hospitals had two indicators of staffing ratios: one for all nurse staffing and one for paediatric nurse staffing.

We also examined the effects of staffing by utilising a contemporary paediatric staffing benchmark of no more than four patients per nurse based upon the state of California's mandated minimum nurse staffing ratios. ${ }^{32}$ This variable was constructed at the hospital level as a dichotomous variable, with a zero indicating that the average hospital paediatric nurse staffing ratio (based on paediatric nurse reports) was greater than four patients per nurse and a one indicating that the average paediatric nurse staffing ratio was less than or equal to four patients per nurse.

A readmission was defined as any repeat hospitalisation occurring within 14 days or between 15 and 30 days of discharge from an index hospitalisation. To account for patient characteristics, we included measures of patient demographics (age, sex, race, payer), a measure of socioeconomic wellbeing for the patient's home zip code based upon publicly available US census data, ${ }^{33}$ primary diagnosis, primary procedure type, comorbidities and illness severity (emergent admission, transfer admission, hospitalisation in the previous year).

Measures of hospital characteristics such as teaching intensity, technology level, bed size and type (children's vs general) were included to account for organisational characteristics that could confound the relationship between staffing levels and readmission. Teaching intensity was modelled as a categorical variable based on the resident-to-bed (RB) ratio: nonteaching $(\mathrm{RB}$ ratio $=0)$, minor teaching intensity $(0<\mathrm{RB}$ ratio $\leq 0.25)$ and major teaching intensity $(\mathrm{RB}$ ratio $>0.25)$. Technology level related to the performance of cardiac and/or solid organ transplant surgery; hospitals performing neither procedure were classified as low-technology hospitals while those performing one or both were classified as high-technology hospitals. Bed size was modelled as a continuous variable. A hospital was classified as a children's hospital if either (1) $90 \%$ or more of patients admitted to the hospital in 2006 were younger than the age of 17 or (2) the hospital was in the top fifth percentile in the state with respect to the volume of paediatric admissions between ages 1 and 17 years, and the hospital also (a) has a paediatric residency programme or (b) has a primary affiliation with a medical school. ${ }^{34}$

We used common identifiers to aggregate nurses and patients within hospitals, though we were unable to link the outcomes of individual patients with data provided by individual nurses. The final sample consisted of data from 14194 RNs and 90459 children in 225 hospitals, 19 of which were children's hospitals. The mean number of total nurse respondents per hospital was 63 (range 10-248) and the mean number of paediatric nurse respondents per hospital was 3.25 (range 1-40); there were 732 paediatric nurses distributed across study hospitals. The study protocol was reviewed and approved by the institutional review board of the University of Pennsylvania.

\section{Risk adjustment and data analysis plan}

Risk adjustment models for readmission at both time points were developed separately for medical and surgical cases by randomly splitting the full samples into estimation and validation samples. We included all the patient variables outlined above and assessed the fit of the models by C-statistics, which ranged from 0.70 to 0.79 for the medical models to 0.82 to 0.85 for surgical models.

Binary and multinomial logit regression models were constructed to estimate the effects of nurse staffing ratios on a child's likelihood of readmission at multiple time points with and without controlling for relevant patient and hospital characteristics. Both approaches yielded nearly equivalent results, so we present results from the binary models for ease of interpretation and discuss only adjusted models. We compared children readmitted in discrete intervals within the first 30 days after discharge to children who did not experience a readmission at any point after their index hospitalisation, and we analysed medical and surgical cases separately. We transformed logit coefficients to ORs and used robust SEs to account for the clustering of patients within hospitals. All analyses were performed using Stata V.11.0 (STATACorp, College Station, Texas, USA), and results were considered statistically significant at $\mathrm{p}<0.05$.

\section{RESULTS}

\section{Descriptive findings}

We had complete data for 90459 paediatric patients, who constituted approximately $67 \%$ of index admissions for the conditions of interest in the four states in 2006. Of these patients, 1075 (1.2\%) were readmitted within 14 days and $656(0.7 \%)$ were readmitted between 15 and 30 days of discharge. Medical cases accounted for $75 \%(n=68321)$ of the overall sample and $96 \%(n=1663)$ of total readmissions. A breakdown of the sample distribution for individual diagnoses and procedures is available in the online supplementary appendix. Table 1 highlights characteristics of the patient sample. Slightly more than half of 
Table 1 Patient sample characteristics ( $n=90$ 459)

\begin{tabular}{lc}
\hline Characteristic & No. (\%) \\
\hline Age (mean, SD) & $7.6(5.4)$ \\
Length of Stay (mean, SD) & $3.0(4.9)$ \\
Male & $50375(55.7)$ \\
Emergency admission & $56176(62.1)$ \\
Transfer admission & $4808(5.3)$ \\
Hospitalisation in previous year & $7585(8.4)$ \\
Medicaid as primary payer & $35245(39.0)$ \\
Non-white race & $51332(56.8)$ \\
Comorbid conditions & \\
$\quad$ None & $72852(80.5)$ \\
1 & $14760(16.3)$ \\
2 or more & $2847(3.2)$ \\
Case type & \\
$\quad$ Medical & $68321(75.5)$ \\
Surgical & $22138(24.5)$ \\
\hline
\end{tabular}

the patients were non-white, and $62 \%$ were admitted to the hospital through the emergency department. Approximately $20 \%$ had a coded comorbidity as a secondary diagnosis and $3.2 \%$ had two or more comorbid conditions. Table 2 shows distributions of hospitals, patients and nurses across numerous hospital characteristics. Approximately $24 \%$ of hospitals were reported by nurses as having paediatric nurse staffing ratios of greater than five patients per nurse. Overall, $68 \%$ of hospitals were reported by nurses as meeting the California paediatric staffing ratio benchmark of four patients per nurse, and $73 \%$ of all patients in the sample were treated in these hospitals. Notably, 35\% of children in the sample were treated in $8 \%$ of hospitals, which were classified as children's hospitals.

\section{Results of logistic regression analyses}

Table 3 displays the univariable effects of patient and hospital characteristics on readmission outcomes across all patients. As expected, patient characteristics had significant unadjusted effects on readmission at both time points, particularly a hospitalisation in the previous year and the presence of multiple comorbid conditions. Staffing ratios also had significant unadjusted effects on readmission outcomes at both time points, and three of four hospital variables had significant effects on readmission within 15-30 days of discharge. We retained all variables in the final adjusted models including those that did not demonstrate statistical significance because of theoretical significance and their established use in prior paediatric outcome studies. ${ }^{14} 15$

The nurse staffing results of the adjusted models are shown in table 4 . The direction of the effects of staffing ratios on likelihood of readmission at both time points was generally consistent with our hypothesis. We did not observe significant effects of hospital
Table 2 Sample distribution across hospital characteristics

\begin{tabular}{|c|c|c|c|}
\hline \multirow[b]{2}{*}{ Characteristic } & \multicolumn{3}{|l|}{ No. (\%) } \\
\hline & $\begin{array}{l}\text { Hospitals } \\
(\mathrm{N}=225)\end{array}$ & $\begin{array}{l}\text { Patients } \\
\text { (N=90459) }\end{array}$ & $\begin{array}{l}\text { Nurses } \\
(\mathrm{N}=14194)\end{array}$ \\
\hline \multicolumn{4}{|c|}{ Staffing ratio, patients per nurse } \\
\hline Fewer than 3 & $2(0.9)$ & $2837(3.1)$ & $42(0.3)$ \\
\hline $3-3.99$ & $52(23.1)$ & $35302(39.6)$ & $3220(22.7)$ \\
\hline $4-4.99$ & $83(36.9)$ & $29137(32.2)$ & $5025(35.4)$ \\
\hline$\geq 5$ & $88(39.1)$ & $23183(25.6)$ & 5907 (41.6) \\
\hline \multicolumn{4}{|c|}{ Staffing ratio, patients per paediatric nurse $(\mathrm{N}=732)$} \\
\hline Fewer than 3 & $29(12.9)$ & $6510(7.2)$ & $71(9.7)$ \\
\hline $3-3.99$ & $75(33.3)$ & $43984(48.6)$ & $349(47.7)$ \\
\hline $4-4.99$ & $66(29.3)$ & $24466(27.1)$ & $190(30.0)$ \\
\hline$\geq 5$ & $55(24.4)$ & $15499(17.1)$ & $122(16.7)$ \\
\hline $\begin{array}{l}\text { Hospitals meeting } C A \\
\text { paediatric ratio }\end{array}$ & $153(68.0)$ & $66284(73.2)$ & $9297(65.5)$ \\
\hline \multicolumn{4}{|l|}{ Bed size } \\
\hline Fewer than 100 & $78(34.7)$ & $21733(24.0)$ & $2813(19.8)$ \\
\hline $100-249$ & $108(48.0)$ & $46978(51.9)$ & $6929(48.8)$ \\
\hline$\geq 250$ & $39(17.3)$ & $21748(24.0)$ & $4452(31.4)$ \\
\hline High technology level & $128(56.9)$ & $67660(74.8)$ & 9602 (67.6) \\
\hline \multicolumn{4}{|l|}{ Teaching intensity } \\
\hline Non-teaching & $85(37.8)$ & $19777(21.9)$ & $4553(32.1)$ \\
\hline Minor teaching & $112(49.8)$ & $46749(51.7)$ & 7065 (49.8) \\
\hline Major teaching & $28(12.4)$ & $23933(26.0)$ & $2576(18.1)$ \\
\hline \multicolumn{4}{|l|}{ Hospital type } \\
\hline General & $206(91.6)$ & $59210(65.5)$ & $12658(89.2)$ \\
\hline Children's & $19(8.4)$ & 31249 (34.5) & $1536(10.8)$ \\
\hline
\end{tabular}

nurse staffing (all nurse staffing or paediatric staffing) on readmissions within 14 days for children in either group, though effects of all nurse staffing on readmission did approach statistical significance at $p<0.10$. In the case of surgical patients, the effect of all nurse staffing on 14-day readmission was the inverse of what was expected.

Higher average nurse staffing ratios in hospitals were strongly and significantly associated with increased odds of readmission for both medical and surgical patients within 15-30 days after discharge. The final adjusted OR (AOR) indicates that each one patient increase in a hospital's average all-nurse staffing ratio increased a medical child's odds of readmission within $15-30$ days by a factor of 1.15 , or $15 \%$ (95\% CI 1.01 to 1.32) after controlling for relevant patient and hospital characteristics. Effects of hospital staffing ratios were strongest and most significant for paediatric nurse staffing ratios; each one patient increase in a hospital's average paediatric staffing ratio increased a medical child's odds of readmission within 15-30 days by a factor of 1.11 , or by $11 \%$ (95\% CI 1.02 to 1.20$)$ and a surgical child's odds of readmission within 15-30 days by a factor of 1.48 , or by $48 \%$ (95\% CI 1.27 to 1.73 ). Thus, as a hospital's average paediatric nurse staffing ratio worsened, a child's likelihood of readmission significantly increased. 
Table 3 Patient and hospital variables as univariable predictors of readmission across all patients

\begin{tabular}{|c|c|c|c|c|}
\hline \multirow[b]{2}{*}{ Variables (estimated separately) } & \multicolumn{2}{|l|}{ Within 14 days } & \multicolumn{2}{|l|}{ 15-30 days } \\
\hline & OR $(95 \% \mathrm{Cl})$ & $\mathrm{p}$ Value & OR $(95 \% \mathrm{Cl})$ & p Value \\
\hline \multicolumn{5}{|l|}{ Patient characteristics } \\
\hline Age & $1.00(0.98$ to 1.01$)$ & 0.57 & $0.97(0.96$ to 0.99$)$ & 0.000 \\
\hline LOS & $1.02(1.01$ to 1.03$)$ & 0.000 & 1.01 (1.01 to 1.02$)$ & 0.002 \\
\hline Sex (male) & $1.14(1.00$ to 1.29$)$ & 0.048 & $1.06(0.91$ to 1.23$)$ & 0.45 \\
\hline ED admission & $1.13(0.94$ to 1.36$)$ & 0.19 & 1.07 (0.89 to 1.28$)$ & 0.50 \\
\hline Transfer admission & $1.28(0.98$ to 1.67$)$ & 0.071 & $1.19(0.83$ to 1.72$)$ & 0.34 \\
\hline Hospitalisation in previous year & 5.75 (4.88 to 6.78$)$ & 0.000 & $8.70(7.26$ to 10.44$)$ & 0.000 \\
\hline Medicaid as primary payer & $1.53(1.32$ to 1.76$)$ & 0.000 & 1.90 (1.55 to 2.32$)$ & 0.000 \\
\hline Non-white race & $1.34(1.15$ to 1.56$)$ & 0.000 & $1.61(1.36$ to 1.90$)$ & 0.000 \\
\hline 1 comorbid condition (compared to none) & 1.85 (1.60 to 2.14$)$ & 0.000 & $2.02(1.62$ to 2.51$)$ & 0.000 \\
\hline 2 or more comorbid conditions (compared to none) & 3.96 (3.21 to 4.89$)$ & 0.000 & 3.64 (2.70 to 4.91$)$ & 0.000 \\
\hline \multicolumn{5}{|l|}{ Hospital characteristics } \\
\hline Major teaching hospital & $1.15(0.98$ to 1.34$)$ & 0.091 & 1.18 (0.99 to 1.42$)$ & 0.068 \\
\hline Hospital bed size & $1.06(0.90$ to 1.24$)$ & 0.52 & $1.31(1.08$ to 1.58$)$ & 0.005 \\
\hline Children's hospital & $1.09(0.87$ to 1.37$)$ & 0.46 & $1.38(1.05$ to 1.82$)$ & 0.021 \\
\hline High technology hospital & $0.93(0.77$ to 1.13$)$ & 0.48 & 1.48 (1.09 to 2.01$)$ & 0.012 \\
\hline Overall patient to $\mathrm{RN}$ ratio & $1.09(1.00$ to 1.19$)$ & 0.046 & $1.07(0.96$ to 1.20$)$ & 0.19 \\
\hline Peds patient to RN ratio & 1.07 (1.01 to 1.14$)$ & 0.035 & 1.17 (1.09 to 1.26$)$ & 0.000 \\
\hline Hospital met CA peds ratio & $0.77(0.62$ to 0.95$)$ & 0.014 & $0.61(0.47$ to 0.79$)$ & 0.000 \\
\hline
\end{tabular}

ED, Emergency Department; RN, Registered Nurse.

Analysis of readmission based on whether hospitals met a contemporary paediatric nurse staffing benchmark also revealed significant effects at the 15-30 day interval; receiving care in a hospital that met the staffing benchmark of four or fewer paediatric patients per nurse was associated with a $24 \%$ decrease in the risk of 15-30 day readmission (AOR: $0.76,95 \%$ CI 0.61 to 0.94 ) for medical patients and a $63 \%$ decrease in the risk of 15-30 day readmission (AOR: 0.37, $95 \%$ CI 0.13 to 1.00 ) for surgical patients.

No significant effects of hospital characteristics were observed in any models except for high technology status on 14-day readmission in medical patients (AOR: $0.75,95 \%$ CI 0.57 to 0.99 ). As expected, patient characteristics exhibited strong and significant effects on readmission across all models including age,
Medicaid as primary payer, non-white race, primary diagnosis/procedure, the presence of comorbid conditions, and a hospitalisation in the previous year.

\section{DISCUSSION}

The results of this study suggest that hospital patient-to-nurse staffing ratios are significantly associated with the likelihood of readmission from 15 to 30 days after discharge for children receiving care for common conditions: each additional patient per nurse added to a hospital's average paediatric staffing ratio was associated with up to an $11 \%$ increase in the odds of readmission within 15-30 days after discharge for medical patients and up to a $48 \%$ increase in the odds of 15-30 day readmission for surgical patients. Further, children treated in hospitals meeting a

Table 4 Final adjusted models of hospital nurse staffing ratios and odds of readmission

\begin{tabular}{|c|c|c|c|c|}
\hline & \multicolumn{2}{|l|}{ Within 14 days } & \multicolumn{2}{|l|}{ 15-30 days } \\
\hline & OR (95\% Cl) & p Value & OR (95\% Cl) & p Value \\
\hline \multicolumn{5}{|l|}{ Medical cases $(n=68294)$} \\
\hline All nurse staffing & 1.10 (0.99 to 1.21$)$ & 0.072 & 1.15 (1.01 to 1.32$)$ & 0.031 \\
\hline Paediatric staffing & 1.01 (0.94 to 1.09$)$ & 0.81 & $1.11(1.02$ to 1.20$)$ & 0.013 \\
\hline Hospital met CA peds ratio & $0.98(0.81$ to 1.19$)$ & 0.85 & $0.76(0.61$ to 0.94$)$ & 0.010 \\
\hline \multicolumn{5}{|l|}{ Surgical cases $(n=22119)$} \\
\hline All nurse staffing & $0.63(0.37$ to 1.06$)$ & 0.082 & 1.57 (0.98 to 2.51$)$ & 0.059 \\
\hline Paediatric staffing & 1.01 (0.78 to 1.31$)$ & 0.93 & $1.48(1.27$ to 1.73$)$ & 0.000 \\
\hline Hospital met CA peds ratio & 1.07 (0.45 to 2.54$)$ & 0.88 & $0.37(0.13$ to 1.00$)$ & 0.050 \\
\hline
\end{tabular}


paediatric staffing benchmark were significantly less likely to experience a readmission. We did not observe significant effects of nurse staffing ratios on readmissions occurring within 14 days of discharge.

The relationship between leaner hospital nurse staffing ratios and higher likelihood of readmission may be explained by nurses having less time to engage in meaningful teaching and discharge preparation due to higher workloads. Nurses manage added workload by cognitively prioritising responsibilities, where imminent clinical concerns and high uncertainty activities are addressed before routine care. ${ }^{35}$ Because patient and family teaching and discharge preparation is generally not considered as urgent as other care needs such as medication administration or responding to clinical deterioration, it may be more likely to be delayed or missed. This interpretation is supported by prior studies of nurse-reported care omissions; Aiken et al $^{36}$ found that approximately $28 \%$ of 43329 surveyed hospital nurses reported not performing essential patient and family teaching on their last shift worked due to lack of time and 13\% reported not having time to prepare patients and families for discharge. A more recent study by Kalisch and colleagues found that of 4086 nurses in 10 hospitals, approximately $5 \%$ reported omitting discharge planning and teaching 'frequently' or 'always'. ${ }^{37}$ Reduced nurse availability as a consequence of workload is also thought to result in decreased awareness of patient conditions and needs. ${ }^{38}{ }^{39}$ Multiple studies have identified unresolved problems during an index hospitalisation as likely contributors to readmission, ${ }^{40-42}$ and one study estimated that up to $37 \%$ of adult hospital readmissions were attributable to hospital systems factors that impact quality. ${ }^{43}$

Our finding that staffing effects are significant for readmission from 15 to 30 days but not for readmissions within the first 14 days after hospital discharge is contrary to our assumptions before the study. We can only speculate as to why early readmissions are not sensitive to hospital nurse staffing. It is possible that staffing levels are associated with other important unmeasured hospital characteristics that correspond to readmission, resulting in confounding of the effects of staffing on early readmission. It is also plausible that for some conditions, particularly surgical conditions, hospital-related complications such as pneumonia or wound infections are not clinically obvious in the immediate post-discharge period, resulting in a later readmission. Additionally, we theorise that paediatric readmissions with 15-30 days may actually be an appropriate metric of hospital quality due to what we term the 'competent caregiver effect'. Unlike many hospitalised adults, ill children are discharged home with caregivers who bear primary responsibility for the child's health and well-being. Despite inadequate discharge preparation or otherwise poor quality care, competent caregivers may be able to manage the child's care at home for an extended period of time until they cannot, at which time they return to the hospital. In essence, hospitalised children may have a caregiver safety net after discharge that many hospitalised adults do not, and this may make the difference between an earlier (within 14 days) and later (15 to 30 days) readmission. ${ }^{44}$ Clearly more research is needed to better understand the reasons for children's readmissions and thus identify which ones are potentially preventable.

While there is ample evidence that patients treated in hospitals with better nurse staffing experience better outcomes, there is limited evidence to determine what the optimal staffing levels should be for a given patient population and/or hospital unit type. We have compared the outcomes of children treated in hospitals that meet the current California mandated staffing ratio of four or fewer paediatric patients per nurse and found that treatment in a hospital meeting this standard significantly reduces the risk of readmission up to $63 \%$. This finding is important because it speaks to the validity of the California minimum staffing ratio for paediatric care, but we emphasise that our results are preliminary and should be tested in further studies.

\section{Limitations}

We cannot confirm causal relationships between nurse staffing levels in hospitals and paediatric readmissions due to the observational and cross-sectional nature of the data. Confounding is a real possibility; we were unable to account for a number of variables that could be associated with both nurse staffing levels and readmission outcomes in our sample such as hospital financial resources, hospital occupancy levels and planned readmissions. We recommend the use of factorial designs in future staffing research, such that the effects of variable staffing levels can be evaluated in a manner that approaches experimental design. ${ }^{45}{ }^{46}$ Similarly, future studies of nursing care quality and hospital readmission should focus on analysis of early preventable readmissions in a sample of hospitals where key contextual variables, such as resources and quality improvement sophistication, are measured and controlled.

We analysed all-cause readmission due to the difficulty in discerning clinical relevance in administrative data, yet recognise that a repeat hospitalisation may either have no relationship to a prior hospitalisation or that it may be perfectly correlated as a planned readmission for ongoing therapeutic care. ${ }^{18}$ We acknowledge that staffing ratios are only one measure of nurses' workloads and are indirect measures of the quality and dose of nursing care that is delivered at the bedside. Process-oriented measures of nursing care, such as adequacy of discharge preparation or missed teaching opportunities, may prove to be correlates of readmission similar to process measures of physician care. $^{40}$ 


\section{Generalisability of findings}

Our finding that leaner nurse staffing levels in hospitals are associated with poorer patient outcomes is consistent with other observational studies of nurse staffing ratios and patient outcomes, including those using other sources of staffing data and varying statistical modelling approaches. However, we suggest additional research on both appropriate paediatric readmission measures and the relationship between nursing care delivery, nurse staffing levels and readmissions.

\section{CONCLUSION}

We have found that average paediatric nurse staffing ratios are significantly associated with hospital readmission for children with common medical and surgical conditions. To our knowledge, this study is the first to explicitly examine and find an association between staffing ratios and hospital readmission in paediatrics.

Our findings have implications for hospital administrators given the national emphasis on reduction of readmissions by payers. The role of nursing care in reducing readmissions has traditionally focused on nurse-led discharge planning programmes in the inpatient setting ${ }^{47-50}$ and nurse-directed home care for patients with complex or chronic conditions. ${ }^{49} 51$ While these nurse-oriented interventions have been shown to significantly reduce readmissions, our findings suggest that hospitals might also achieve reductions in readmission by focusing on the number of patients assigned to nurses. In paediatrics, limiting nurses' workloads to four or fewer patients appears to have benefits in reducing readmissions.

Further, hospitals are earnestly examining their discharge processes and implementing quality improvement programmes aimed at preparing patients and families to manage health condition(s) beyond the hospital. Quality improvement initiatives to improve inpatient care delivery often depend upon the sustained efforts of front-line workers, particularly nurses. Prior research shows that hospitals with better nurse staffing ratios deliver Joint Commission-recommended care for key conditions more reliably, ${ }^{52}$ highlighting the inter-relationship of nurse staffing levels and quality improvement success. The sustainability of quality improvement initiatives related to paediatric readmission may ultimately depend on nurses' ability to direct meaningful time and attention to such efforts.

Acknowledgements We would like to thank Tim Cheney for technical support. Presentations at the 2011 AcademyHealth Annual Research Meeting contained a preliminary review of these data.

Contributors Conception and Design: HLTC, JPC, DMS, JHS, LHA; Acquisition of Data: LHA, JPC; Analysis and Interpretation: HLTC, LHA, JHS, JPC, DMS; Drafting/ Revision: HLTC, LHA.

Funding Research support was provided by the Agency for Healthcare Research and Quality (R36-HS018802, Tubbs Cooley, PI) and the National Institute for Nursing Research (T32-NR007104 and R01-NR04513, Aiken, PI). The content is solely the responsibility of the authors and does not necessarily represent the official views of the funding agencies.

Competing interests None.

Ethics approval Institutional Review Board at the University of Pennsylvania.

Provenance and peer review Not commissioned; externally peer reviewed.

Open Access This is an Open Access article distributed in accordance with the Creative Commons Attribution Non Commercial (CC BY-NC 3.0) license, which permits others to distribute, remix, adapt, build upon this work non-commercially, and license their derivative works on different terms, provided the original work is properly cited and the use is non-commercial. See: http://creativecommons.org/licenses/by-nc/3.0/

\section{REFERENCES}

1 Carrns A. Farewell, and don't come back: health reform gives hospitals a big incentive to send patients home for good. U.S. News World Rep 2010;147:20-3.

2 Axon RN, Williams MV. Hospital readmission as an accountability measure. JAMA 2011;305:504-5.

3 Center for Medicare and Medicaid Innovation. Community-based Care Transitions Program. http://innovations.cms.gov/initiatives/ Partnership-for-Patients/CCTP/index.html (accessed 8 Jun 2012).

4 Gay JC, Hain PD, Grantham JA, et al. Epidemiology of 15-day readmissions to a children's hospital. Pediatrics 2011;127: e1505-12.

5 Berry JG, Hall DE, Kuo DZ, et al. Hospital utilization and characteristics of patients experiencing recurrent readmissions within children's hospitals. JAMA 2011;305:682-90.

6 Mackie A, Ionescuittu R, Pilote L, et al. Hospital readmissions in children with congenital heart disease: A population-based study. Am Heart J 2008;155:577-84.

7 Czaja AS, Zimmerman JJ, Nathens AB. Readmission and late mortality after pediatric severe sepsis. Pediatrics 2009;123:849-57.

8 Feudtner C, Levin JE, Srivastava R, et al. How well can hospital readmission be predicted in a cohort of hospitalized children? A retrospective, multicenter study. Pediatrics 2009;123:286-93.

9 Chen Y, Dales R, Stewart P, et al. Hospital readmissions for asthma in children and young adults in Canada. Pediatr Pulmonol 2003;36:22-6.

10 Minkovitz CS, Andrews JS, Serwint JR. Rehospitalization of children with asthma. Arch Pediatr Adolesc Med 1999;153:727-30.

11 Bloomberg GR, Trinkaus KM, Fisher EB, et al. Hospital readmissions for childhood asthma: a 10-year metropolitan study. Am J Respir Crit Care Med 2003;167:1068-76.

12 Frei-Jones MJ, Field JJ, DeBaun MR. Risk factors for hospital readmission within 30 days: a new quality measure for children with sickle cell disease. Pediatr Blood Cancer 2009;52:481-5.

13 Samuels BN, Novack AH, Martin DP, et al. Comparison of length of stay for asthma by hospital type. Pediatrics 1998;101:e13.

14 Silber JH, Rosenbaum PR, Koziol LF, et al. Conditional length of stay. Health Serv Res 1999;34(1 Pt 2):349-63.

15 Lorch SA, Zhang X, Rosenbaum PR, et al. Equivalent lengths of stay of pediatric patients hospitalized in rural and nonrural hospitals. Pediatrics 2004;114:e400-8.

16 Feudtner C, Pati S, Goodman DM, et al. State-level child health system performance and the likelihood of readmission to children's hospitals. J Pediatr 2010;157:98-102.e1.

17 Lorch SA, Baiocchi M, Silber JH, et al. The role of outpatient facilities in explaining variations in risk-adjusted readmission rates between hospitals. Health Serv Res 2010;45:24-41. 
18 Hain PD, Gay JC, Berutti TW, et al. Preventability of early readmissions at a children's hospital. Pediatrics 2013;131:e171-81.

19 Weiss M, Johnson NL, Malin S, et al. Readiness for discharge in parents of hospitalized children. J Pediatr Nurs 2008;23:282-95.

20 Aiken LH, Cimiotti J, Sloane DM, et al. The effects of nurse staffing and nurse education on patient deaths in hospitals with different nurse work environments. Med Care 2012;49:1047-53.

21 Aiken LH, Sermeus W, Van den Heede K, et al. Patient safety, satisfaction, and quality of hospital care: cross-sectional surveys of nurses and patients in 12 countries in Europe and the United States. BMJ 2012;344:e1717.

22 Kane RL, Shamliyan TA, Mueller C, et al. The association of registered nurse staffing levels and patient outcomes. Systematic review and meta-analysis. Med Care 2007;45:1195-204.

23 Needleman J, Buerhaus P, Pankratz S, et al. Nurse staffing and inpatient hospital mortality. N Engl J Med 2011;364:1037-45.

24 Mark BA, Harless DW, Berman WF. Nurse staffing and adverse events in hospitalized children. Policy Polit Nurs Pract 2007;8:83-92.

25 Mark BA, Harless DW, McCue M, et al. A longitudinal examination of hospital registered nurse staffing and quality of care. Health Serv Res 2004;39:279-300.

26 Weiss ME, Yakusheva O, Bobay K. Quality and cost analysis of nurse staffing, discharge preparation, and postdischarge utilization. Health Serv Res 2011;46:1473-94.

27 McHugh M, Ma C. Hospital nursing and 30-day readmissions among medicare patients with heart failure, acute myocardial infarction, and pneumonia. Med Care 2013;51:52-9.

28 Smith HL. A double sample to minimize bias due to non-response in a mail survey. In: Ruiz-Gazen A, Guilbert P, Haziza D, Tille Y, eds. Survey methods: applications to longitudinal studies, to health, to electoral studies, and to studies in developing countries. Paris: Dunod, 2008:334-9.

29 Silber JH, Gleeson SP, Zhao H. The influence of chronic disease on resource utilization in common acute pediatric conditions: Financial concerns for children's hospitals. Arch Pediatr Adolesc Med 1999;153:169-79.

30 Lake ET, Friese CR. Variations in nursing practice environments: relation to staffing and hospital characteristics. Nurs Res 2006;55:1-9.

31 Harless DW, Mark BA. Nurse staffing and quality of care with direct measurement of inpatient staffing. Med Care 2010;48:659-63.

32 California Department of Public Health. Nurse-to-Patient Staffing Ratio Regulations. http://www.cdph.ca.gov/services/ DPOPP/regs/Pages/N2PRegulations.aspx (accessed 1 Jul 2012).

33 Carthon JM Brooks, Kutney-Lee A, Jarrín O, et al. Nurse staffing and postsurgical outcomes in black adults. J Am Geriatr Soc 2012;60:1078-84.

34 Silber JH, Rosenbaum PR, Even-Shoshan O, et al. Length of stay, conditional length of stay, and prolonged stay in pediatric asthma. Health Serv Res 2003;38:867-86.

35 Patterson ES, Ebright P, Saleem JJ. Investigating stacking: How do registered nurses prioritize their activities in real-time? Int J Ind Ergon 2011;41:389-93.

36 Aiken LH, Clarke SP, Sloane DM, et al. Nurses' reports on hospital care in five countries: the ways in which nurses' work is structured have left nurses among the least satisfied workers, and the problem is getting worse. Health Aff (Millwood) 2001;20:43-53.

37 Kalisch BJ, Tschannen D, Lee H, et al. Hospital variation in missed nursing care. Am J Med Qual 2011;26:291-9.

38 Kutney-Lee A, Lake ET, Aiken LH. Development of the hospital nurse surveillance capacity profile. Res Nurs Health 2009;32:217-28.

39 Clarke SP, Aiken LH. Failure to rescue: needless deaths are prime examples of the need for more nurses at the bedside. Am J Nurs 2003;103:42-7.

40 Ashton CM, Kuykendall DH, Johnson ML, et al. The Association between the quality of inpatient care and early readmission. Ann Intern Med 1995;122:415-21.

41 Ashton C, Del Junco D, Souchek J, et al. The association between the quality of inpatient care and early readmission: a meta-analysis of the evidence. Med Care 1997;35: 1044-59.

42 Benbassat J, Taragin M. Hospital readmissions as a measure of quality of health care: advantages and limitations. Arch Intern Med 2000;160:1074-81.

43 Oddone EZ, Weinberger M, Horner M, et al. The Veterans Affairs Cooperative Studies in Health Services Group on Primary Care and Hospital Readmissions. Classifying general medicine readmissions. J Gen Intern Med 1996;11:597-607.

44 Tao H, Ellenbecker CH, Chen J, et al. The influence of social environmental factors on rehospitalization among patients receiving home health care services. ANS Adv Nurs Sci 2012;35:346-58.

45 U.K. Neonatal Staffing Study Group. Patient volume, staffing, and workload in relation to risk-adjusted outcomes in a random stratified sample of UK neonatal intensive care units: a prospective evaluation. Lancet 2002;359:99-107.

46 Barnes S, Golden B, Wasil E, et al. An application of factorial design to compare the relative effectiveness of hospital infection control measures. Proceedings of the 2011 Winter Simulation Conference; 1283-1294. http://www.informs-sim. org/wsc11 papers/115.pdf (accessed 28 Jan 2013).

47 Manning S. Bridging the gap between hospital and home: a new model of care for reducing readmission rates in chronic heart failure. J Cardiovasc Nurs 2011;26:368-76.

48 Naylor MD, Brooten DA, Campbell RL, et al. Transitional care of older adults hospitalized with heart failure: a randomized, controlled trial. J Am Geriatr Soc 2004;52:675-84.

49 Rich MW, Beckham V, Wittenberg C, et al. A multidisciplinary intervention to prevent the readmission of elderly patients with congestive heart failure. N Engl J Med 1995;333:1190-5.

50 Wesseldine L, McCarthy P, Silverman M. Structured discharge procedure for children admitted to hospital with acute asthma: a randomised controlled trial of nursing practice. Arch Dis Child 1999;80:110-14.

51 Dennis L, Blue C, Stahl S, et al. The relationship betwen hospital readmissions of medicare beneficiaries with chronic illnesses and home care nursing interventions. Home Healthc Nurse 1996;14:303-9.

52 Landon BE, Normand ST, Lessler A, et al. Quality of care for the treatment of acute medical conditions in US hospitals. Arch Intern Med 2006;166:2511-17. 